\title{
Interactive comment on "Analysis of atmospheric ammonia over South and East Asia based on the MOZART-4 model and its comparison with satellite and surface observations" by Pooja V. Pawar et al.
}

\section{Pooja V. Pawar et al.}

poojapawar5997@gmail.com

Received and published: 9 February 2021

The comment was uploaded in the form of a supplement:

https://acp.copernicus.org/preprints/acp-2020-639/acp-2020-639-AC4-supplement.pdf

Interactive comment on Atmos. Chem. Phys. Discuss., https://doi.org/10.5194/acp-2020-639, 2020. 